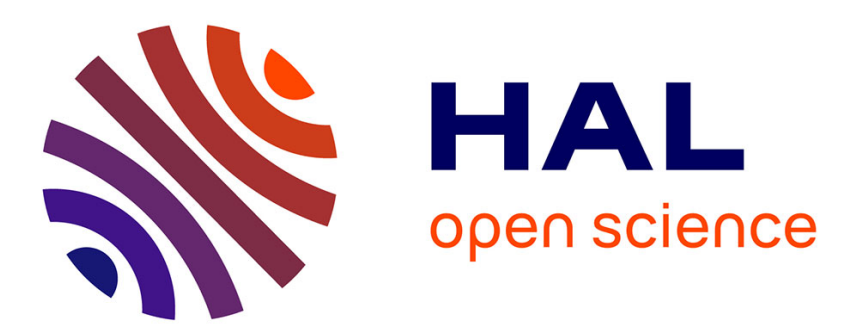

\title{
Integrate Product Planning Process of OKP Companies in the Cloud Manufacturing Environment
}

\author{
Pai Zheng, Xun Xu, Sheng Quan Xie
}

\section{To cite this version:}

Pai Zheng, Xun Xu, Sheng Quan Xie. Integrate Product Planning Process of OKP Companies in the Cloud Manufacturing Environment. IFIP International Conference on Advances in Production Management Systems (APMS), Sep 2015, Tokyo, Japan. pp.420-426, 10.1007/978-3-319-22759-7_49 . hal-01431125

\section{HAL Id: hal-01431125 \\ https://hal.inria.fr/hal-01431125}

Submitted on 10 Jan 2017

HAL is a multi-disciplinary open access archive for the deposit and dissemination of scientific research documents, whether they are published or not. The documents may come from teaching and research institutions in France or abroad, or from public or private research centers.
L'archive ouverte pluridisciplinaire HAL, est destinée au dépôt et à la diffusion de documents scientifiques de niveau recherche, publiés ou non, émanant des établissements d'enseignement et de recherche français ou étrangers, des laboratoires publics ou privés. 


\title{
Integrate product planning process of OKP companies in the cloud manufacturing environment
}

\author{
Pai Zheng1a, Xun Xu1b and Sheng Quan Xie1c* \\ ${ }_{1}$ Department of Mechanical Engineering, University of Auckland, Private Bag 92019, \\ Auckland, New Zealand \\ a pzhe539@aucklanduni.ac.nz, bxun.xu@auckland.ac.nz,

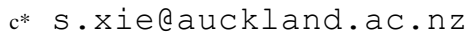

\begin{abstract}
In today's competitive market, OKP companies operate in the "engineer-to-order" business mode, whereby analysing the "voice of customer" promptly and accurately in the early design stage determines the success of product development. However, OKP companies have limited resources. They may not be able to afford the cost of the complicated Quality Function Deployment (QFD) product planning process, nor can they obtain abundant CRs information effectively in traditional internet-based environment. This paper proposes a QFD-based approach in the cloud manufacturing (CMfg) environment to enhance OKP companies' product planning process. CMfg (a newly emerged manufacturing paradigm) utilizes advanced information technologies and business mode, which may provide sufficient and cost-effective resources to OKP companies. The interaction process among different cloud service roles is introduced in detail, which contains six main parts: pre-process, identify CRs, competitive marketing analysis, determine final importance ratings, mapping CRs to engineering characteristics (ECs), and customer-centric decision making.
\end{abstract}

Keywords: One-of-a-kind production, cloud manufacturing, product planning, quality function deployment 


\section{Introduction}

One-of-a-Kind Production (OKP) companies aim to produce customized products based on the requirements of individual customer while maintaining the quality and efficiency of mass production [1]. Analysing customer requirements (CRs) accurately and effectively in the product planning stage is critical for the survival of an OKP company [2]. Quality function deployment (QFD), introduced by Akao [3], provides a systematic way (named House of Quality (HoQ)) to catalogue the perceived CRs and to translate them into engineering characteristics (ECs) in the product planning stage. However, OKP companies are mostly Small or Medium sized Enterprises (SMEs), they might not afford the high cost of complicated QFD process, nor can they obtain sufficient customer information effectively in the web-based environment [4].

This paper proposes a QFD-based approach to enhance OKP companies' product planning process in the CMfg environment. For OKP companies, one key benefit of CMfg is the "pay-per-use" mode. They can pay a periodic subscription or utilization fee with minimal upfront costs [5], which they may either out sourcing the QFD product planning process to a team of experts or utilizing online software-as-a-service ( $\mathrm{SaaS}$ ) to deal with it in an cost-effective way. Another key benefit is the utilization of cloud-computing information technology. OKP companies may get abundant product planning resources from multiple sources such as social media (e.g. Facebook), crowdsourcing, resource pooling and etc [6]. The rest of the paper is organized as follows. Section 2 provides a review of cloud manufacturing aspect and QFD-based product planning. Section 3 proposes the QFD-based product planning interaction process of OKP companies in the CMfg environment. Section 4 summarizes the main work of this paper and the future work.

\section{$2 \quad$ Literature review}

\subsection{Cloud manufacturing}

Cloud manufacturing is a newly emerged manufacturing paradigm, Li et al. [7] defined it as a computing and service-oriented manufacturing model developed from the existing advanced manufacturing models and information technologies. It aims to realize a full-scale sharing and circulation, high utilization, and on-demand use of various manufacturing resources and capabilities by providing safe and reliable, high quality, cheap and on-demand used manufacturing services for the whole lifecycle of 
manufacturing [8]. Though there is not a standard definition for CMfg, most of the current definitions share some common traces, such as manufacturing resource, capability, services and platform $[6,7,9,10]$. The main characteristics of CMfg include on-demand, self-service, ubiquitous network access, rapid scalability, resource pooling, and virtualization [6]. With the cloud approach, there is little need for enterprises to make capital investments in manufacturing equipment, or even recruiting engineer experts. Instead, they have the flexibility to manage their own businesses, and could have instant access to business solutions on "pay-per-use" [5]. Though much work has been done in the CMfg area, there is no emphasis on the product planning stage.

\subsection{QFD-based product planning}

Quality function deployment (QFD), introduced by Akao [3], has been a widely adopted customer-oriented methodology in assisting product development process. It provides a systematic way to catalogue the perceived needs of the customer and to translate them into design specifications, all over product planning, product design, process design, and production planning [11]. The key element of QFD is a combined chart of HoQ to map the CRs (the 'WHATs') into ECs (the 'HOWs') that must be adjusted to fulfill the customer needs in product planning stage, and subsequently into parts characteristics, process plans, and manufacture operations [12]. In general, QFD-based product planning contains four steps: 1 . identify CRs; 2 . conduct competitive analysis; 3. determine final importance ratings of CRs; 4. map CRs into ECs.

\section{QFD-based product planning interaction process in the CMfg}

In the CMfg environment, the proposed QFD-based approach of product planning interaction process is shown in Figure 1. Cloud service infrastructure provider, as a third-party provider, hosts virtualized computing resources over the Internet; Cloud service platform provider, is a third-party provides a platform allowing service provider and demander to develop, run and manage Web applications without building and maintaining the infrastructure; Cloud service provider, is an entity that provides services in the cloud service platform; Cloud service demander, is an entity that consumes services offered by the cloud service provider. OKP companies, acting as the service providers, are integrated intelligently in this distributed environment through cloud-based platform system with graphical user interfaces (GUIs). Thus, there is a 
big reduction of investment on the up-front costs. The proposed process includes six main parts and each part contains several steps, which is introduced as follows.

\subsection{Pre-process}

Users request their cloud services (Step 1). If uncertain about their request, they first interact with the infrastructure provider. It offers the search engine with abundant storage of data for them to narrow down their request scope (Step 2). After searching, the infrastructure provider retrieves the historical information with a list of potential platform providers (Step 3) for users to select a proper one according to their preferences (Step 4). However, if they are capable, they may skip the Step 2 to Step 4, and directly interact with the specific platform provider.

Then, the platform provider would be responsible for assessing customer requests through the process of request acquisition (Step 5), request retrieval (Step 6) and request allocation (Step 7 and 8) [5]. The request acquisition is responsible for capturing and deriving useful user information by online inquiry and quoting. Request retrieval is carried out based on the historical design information stored in the service database so at to find out the feasible service providers (known as "service composition") [10]. This process helps enhance resource allocation by modifying unreasonable service requirements to those that the system is able to undertake. Therefore, system efficiency is enhanced and service quality is guaranteed. Request allocation is conducted after comparing the initial service requirements with the design capabilities of the product design resources in the system. User requests are allocated intelligently to the prospective service providers according to the selection of the users.

\subsection{Identify CRs}

In order to satisfy customer needs and gain profits, OKP companies need to take considerable efforts to identify and acquire CRs effectively (Step 9 and Step 10). There are many methods available to collect CR candidates, including focus group, individual interviews, listening and watching, complaints, natural field contact, warranty data, feedback, affinity diagram, and cluster analysis [13]. Then customers are asked to express their perceptions on each $\mathrm{CR}$, as the fundamental importance ratings of CRs. Due to the cloud-based environment, OKP companies may get sufficient CRs information through resource pooling, crowd sourcing, social media and etc. 


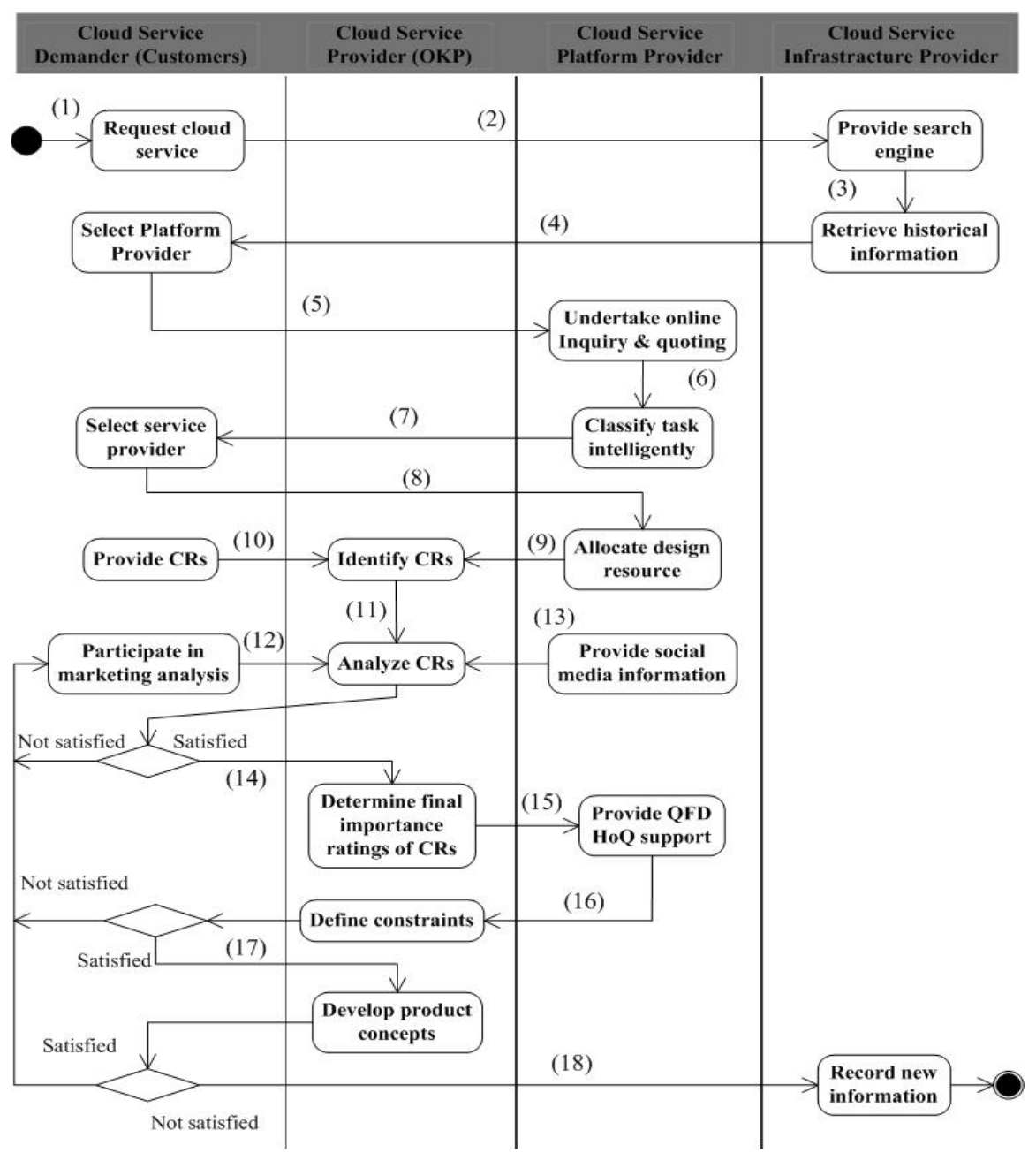

Fig. 1. Product planning interaction process in CMfg

\subsection{Undertake competitive marketing analysis}

Due to the networked environment, both marketing analysts and customers can easily participate in the marketing analysis process through GUIs (Step 12). The platform provider could offer related design information by social media (Step 13), such as competitors' information, customer view histories and etc.

The competitive marketing analysis of CRs (Step 11) can generally be obtained by analyzing relative performance estimations of a corporation and its competitors from customers' perceptions. It utilizes entropy method to obtain the competitive priority 
ratings of CRs [14]. Then, the improvement factors of CRs will be estimated by the engineers in five perspectives: financial, customer, internal-business processes, learning and growth, and feasibility in a qualitative and quantitative way [13].

\subsection{Determine final importance ratings of CRs}

In order to determine the final importance ratings of CRs (Step 14), conjoint analysis [15] is widely utilized. Also, to deal with the imprecise information of CRs, both fuzzy set based methods and rough set based methods are introduced to quantify the subjective information, such as fuzzy AHP [16], fuzzy weighted average [17] and rough number method [18]. They can be implemented in the cloud environment as a SaaS for OKP companies to purchase in a "pay-per-use" mode.

\subsection{Map CRs into ECs}

After Step 14, designers can map CRs into ECs, and transfer the final importance ratings of CRs into importance ratings of ECs by QFD product planning HoQ, which is supported by the platform provider with a team of experts (Step 15). OKP companies may either choose to out sourcing the complicated QFD process or inquire experts with specific knowledge. Accordingly, designers define the constraints of ECs (Step 16) and develop product concepts (Step 17) to customers' satisfaction. Finally, new design information is stored in the cloud server for knowledge re-uses (Step 18).

\subsection{Customer-centric decision making}

Customers need to make their own decisions along the interaction process, i.e.: perceptions towards the CRs (Step 10), fundamental importance ratings of CRs (Step 12), marketing analysis results of CRs (Step 14), the prospective ECs (Step 16), and the design concepts (Step 17). Each step needs to be satisfied by the customers through online negotiations [19]; otherwise, the analysis process needs to be re-conducted from the step of providing and identifying CRs (Step 9 and Step 10).

The above interaction process improves the response speed by connecting customers and service providers in the cloud-based platform collaboratively. Thus, resources can be efficiently utilized by them, which enhance business performance. Also, cloud service platform provider provides online SaaS and social media to support the QFD HoQ while OKP companies only need to pay-per-use. It effectively overcomes their 
shortage of limited resources, and reduces the cost of complicated product planning.

\section{Discussions}

Aiming to enhance the OKP company product planning process, this paper proposed a QFD-based approach to integrate it in the CMfg environment. The approach took advantage the advanced CMfg technologies, which overcomes the challenge of achieving sufficient customer information by utilizing resource pooling, crowd sourcing and social media in the networked environment. Also, it shows how to undertake complicated systematic QFD-based product planning in a cost-effective way by out sourcing the service or utilizing online SaaS and inquire experts in a "pay-per-use" mode. Moreover, the QFD-based interaction process among customers, OKP companies, platform providers and infrastructure providers was introduced in detail, which provided the guidelines for OKP companies to be involved in the CMfg environment. In the future, the proposed approach will be developed with a system framework and a software implementation to facilitate OKP companies' product planning process in the CMfg environment.

\section{Acknowledgement}

Authors wish to acknowledge the financial support provided by the China Scholarship Council and the University of Auckland Joint Scholarship.

\section{Reference}

1. Xie, S.S. and Y. Tu, Rapid One-of-a-kind Product Development: Strategies, Algorithms and Tools. 2011: Springer Science \& Business Media.

2. Xie, S.Q. and Y.L. Tu, Rapid one-of-a-kind product development. International Journal of Advanced Manufacturing Technology, 2006. 27(5-6): p. 421-430.

3. Akao, Y., New product development and quality assurance-quality deployment system. Standardization and Quality Control, 1972. 25(4): p. 7-14.

4. Zhou, Z., et al., An analytical approach to customer requirement information processing. Enterprise Information Systems, 2013. 7(4): p. 543-557.

5. Lu, Y., X. Xu, and J. Xu, Development of a Hybrid Manufacturing Cloud. Journal of Manufacturing Systems, 2014. 33(4): p. 551-566. 
6. Wu, D., et al., Enhancing the Product Realization Process With Cloud-Based Design and Manufacturing Systems. Journal of Computing and Information Science in Engineering, 2013. 13(4).

7. Li, B.-H., et al., Cloud manufacturing: a new service-oriented networked manufacturing model. Computer Integrated Manufacturing Systems, 2010. 16(1): p. 1-7.

8. Tao, F., et al., Cloud manufacturing: a computing and service-oriented manufacturing model. Proceedings of the Institution of Mechanical Engineers Part B-Journal of Engineering Manufacture, 2011. 225(B10): p. 1969-1976.

9. Xu, X., From cloud computing to cloud manufacturing. Robotics and Computer-Integrated Manufacturing, 2012. 28(1): p. 75-86.

10. Zhang, L., et al., Cloud manufacturing: a new manufacturing paradigm. Enterprise Information Systems, 2014. 8(2): p. 167-187.

11. Goncalves-Coelho, A.M., Improving the use of QFD with Axiomatic Design. Concurrent Engineering, 2005. 13(3): p. 233-239.

12. Luo, X., et al., QFD-Based Product Planning With Consumer Choice Analysis. Systems, Man, and Cybernetics: Systems, IEEE Transactions on, 2015. 45(3): p. 454-461.

13. Li, Y.-L., K.-S. Chin, and X.-G. Luo, Determining the final priority ratings of customer requirements in product planning by MDBM and BSC. Expert systems with Applications, 2012. 39(1): p. 1243-1255.

14. Chan, L.-K. and M.-L. Wu, A systematic approach to quality function deployment with a full illustrative example. Omega, 2005. 33(2): p. 119-139.

15. Griffin, A. and J.R. Hauser, The voice of the customer. Marketing science, 1993. 12(1): p. $1-27$.

16. Ayag, Z., A fuzzy AHP-based simulation approach to concept evaluation in a NPD environment. Iie Transactions, 2005. 37(9): p. 827-842.

17. Chen, Y.Z., R.Y.K. Fung, and J.F. Tang, Rating technical attributes in fuzzy QFD by integrating fuzzy weighted average method and fuzzy expected value operator. European Journal of Operational Research, 2006. 174(3): p. 1553-1566.

18. Zhai, L.-Y., L.-P. Khoo, and Z.-W. Zhong, A rough set based decision support approach to improving consumer affective satisfaction in product design. International Journal of Industrial Ergonomics, 2009. 39(2): p. 295-302.

19. Altun, K., T. Dereli, and A. Baykasoglu, Development of a framework for customer co-creation in NPD through multi-issue negotiation with issue trade-offs. Expert Systems with Applications, 2013. 40(3): p. 873-880. 